\title{
EFEITO DE Brachiaria decumbens NA HERBIVORIA E NO Desenvolvimento de Duas leguminosas nativas de CerRado ${ }^{1}$
}

\author{
Effect of Brachiaria decumbens on Herbivory and Development of Two Cerrado Native \\ Leguminosae Species
}

PIRES, A.C.V. ${ }^{2}$, PEREIRA, S.R. ${ }^{3}$, FERNANDES, G.W. ${ }^{4}$ e OKI, Y. ${ }^{4}$

\begin{abstract}
RESUMO - Este estudo avaliou o impacto da presença da gramínea exótica (Brachiaria decumbens) na herbivoria e no desenvolvimento de plântulas de espécies nativas (Hymenaea stigonocarpa e Dipteryx alata) de Cerrado. Para avaliar o impacto da presença da gramínea, 10 blocos em pastagem (antiga área de Cerrado) na Embrapa Gado de Corte (Campo GrandeMS) foram demarcados em janeiro de 2009. As gramíneas foram mantidas intactas em metade dos blocos e, na outra metade, foram removidas. Em cada tratamento, foram avaliados a herbivoria, a altura e o diâmetro na altura do solo (DAS) de 25 plântulas de cada espécie ao longo do ano. O conteúdo de carbono, nitrogênio e água das folhas também foi quantificado. Plântulas de Hymenaea stigonocarpa nos tratamentos com gramínea tiveram maior taxa de crescimento em diâmetro que as plântulas no tratamento sem gramíneas. As plântulas de Dipteryx alata que estavam no tratamento sem gramíneas tiveram maiores taxas de crescimento em altura que as do tratamento com gramíneas. Houve diferença na taxa de herbivoria de D. alata entre os tratamentos. As plântulas das duas espécies que estavam no tratamento com gramínea mostraram maiores concentrações de carbono e menores de água. O conteúdo de nitrogênio foliar foi maior no tratamento com gramíneas que no sem gramíneas em $D$. alata; já o nitrogênio em $H$. stigonocarpa não variou entre os tratamentos. Esses resultados mostram que cada espécie nativa possui distintas respostas fisiológicas e suscetibilidade à herbivoria em ambientes sob competição de recursos com a gramínea exótica, B. decumbens.
\end{abstract}

Palavras-chave: competição, crescimento, Dipteryx alata, gramíneas, Hymenaea stigonocarpa.

ABSTRACT - This study evaluated the impact of the presence of the exotic grass (Brachiaria decumbens) on the herbivory and development of seedlings of native species (Hymenaea stigonocarpa and Dipteryx alata) of the Cerrado. Thus, 10 pasture plots (former Cerrado) at the Embrapa Gado de Corte (Campo Grande-MS) were demarcated in January 2009. The grasses were kept intact in half of the plots and were removed in the other half. In each treatment, the herbivory, as well as height and diameter at ground level (DGL) of 25 seedlings of each species were evaluated during one year. Carbon, nitrogen and water content of the leaves in each treatment were also quantified. Seedlings of Hymenaea stigonocarpa in plots without grasses had higher diameter growth rates than seedlings in plots with grasses. Dipteryx alata seedlings grown in plots without grasses had a higher height growth rate than seedlings grown in plots with grasses. There was a difference in the herbivory rate of $\boldsymbol{D}$. alata between treatments. Seedlings of plots with grasses for the two species showed a higher concentration of carbon and lower amount of water. The leaf nitrogen content was higher in plots with grasses than without grasses in $\boldsymbol{D}$. alata, while nitrogen in $\boldsymbol{H}$. stigonocarpa did not vary between treatments. These results showed that each native species had distinct physiological responses and susceptibility to herbivory in environments under resource competition with the exotic grass $\boldsymbol{B}$. decumbens.

Keywords: competition, growth, Dipteryx alata, grasses, Hymenaea stigonocarpa.

Recebido para publicação em 2.8.2011 e aprovado em 1‥6.2012.

2 Bióloga, Programa de Pós-Graduação em Ecologia, Conservação e Manejo da Vida Silvestre, Universidade Federal de Minas Gerais (UFMG), Caixa Postal 486, 30161-970 - Belo Horizonte, MG, <carol.vipi@gmail.com>; ${ }^{3}$ Universidade Federal de São Carlos UFSCar - Centro de Ciências Biológicas e da Saúde - Via Washington Luiz Km 235 - 13565-905, <silviarahe@gmail.com>; ${ }^{4}$ Ecologia Evolutiva e Biodiversidade /DBG, ICB/Universidade Federal de Minas Gerais - UFMG, Telefone: 55-31-3409-2592, Caixa Postal 486,30161-970 - Belo Horizonte, MG, Brasil, <yumioki1@gmail.com>, <gw.fernandes@gmail.com>.

Planta Daninha, Viçosa-MG, v. 30, n. 4, p. 737-746, 2012 


\section{INTRODUÇÃO}

O desmatamento e o uso da terra são as principais causas da redução das áreas de Cerrado. Atualmente metade dos 2 milhões de $\mathrm{km}^{2}$ da área original do Cerrado está transformada em pastagens plantadas e outro tipos de uso (Klink \& Machado, 2005). Apesar de a regeneração natural ser possivel em áreas de pastagens, raramente a composição de espécies é a mesma, comparada com o ambiente original (Celis \& Jose, 2011).

No Brasil, várias espécies de gramíneas africanas, como Brachiaria decumbens, foram introduzidas acidentalmente ou para fins forrageiros, tornando-se invasoras de ecossistemas naturais, principalmente dos ambientes abertos, como campos e cerrados (Matos \& Pivello, 2009). Alguns fatores contribuíram para seu sucesso como invasora: grande capacidade de dispersão por reprodução vegetativa e por sementes, ciclo reprodutivo rápido, alta eficiência fotossintética e na utilização de nutrientes, altas taxas de crescimento, tolerância ao desfolhamento, herbivoria e queimadas (Levine et al., 2003).

As gramíneas exóticas podem causar efeitos negativos no estabelecimento e desenvolvimento das espécies nativas. Elas competem com as plantas nativas pelo recurso nutricional do solo, que pode acarretar mudança na morfofisiologia vegetal e na quantidade e qualidade dos nutrientes absorvidos pela planta (Rizzardi et al., 2001). Esse estresse nutricional influencia a produção de substâncias de defesa vegetal (Silva \& Batalha, 2011), aumentando a vulnerabilidade a vários grupos de herbivoros (Eichhorn et al., 2010). No entanto, a intensidade da competição e seus efeitos dependerão do tipo de gramínea e das espécies nativas envolvidas (Celis \& Jose, 2011).

Cada espécie vegetal possui algumas características morfológicas (como espinhos e cutícula espessa) e, principalmente, químicas (nutrientes e metabólitos secundários), que minimizam a herbivoria e definem as relações entre os herbivoros (Futuyma \& Agrawal, 2009). Em alguns casos, sobretudo em ambientes mais intensamente afetados por distúrbios, a pressão seletiva da herbivoria pode ser intensa e dificultar o estabelecimento e o desenvolvimento vegetal em um ambiente particular (Eichhorn et al., 2010).

Aspectos da fenologia foliar podem também influenciar os danos causados pelos herbívoros. Plantas que produzem folhas quando a abundância de insetos é baixa conseguem escapar temporalmente da herbivoria, enquanto plantas que produzem as folhas sincronicamente com a maior abundância dos herbívoros são mais suscetiveis a eles (Forkner et al., 2008).

Apesar de a formação de pastagens ser uma das principais causas do desmatamento no Cerrado, ainda faltam estudos sobre a real magnitude da pressão seletiva da herbivoria no estabelecimento de espécies nativas nessas áreas. Alguns poucos estudos sobre o assunto evidenciam que as altas taxas de herbivoria, agregada à competição com gramíneas exóticas, afetam intensamente a sobrevivência e o crescimento de plântulas de espécies arbóreas (Sady et al., 2010).

A fim de contribuir para o sucesso no estabelecimento de espécies nativas do Cerrado em áreas de pastagem, o objetivo deste estudo foi avaliar a herbivoria, a abscisão de folíolos, o desenvolvimento e o teor nutricional de plântulas de Dipteryx alata e Hymenaea stigonocarpa, em presença e ausência de Brachiaria decumbens.

Essas duas espécies de crescimento tardio, frequentes no Cerrado, são membros representativos da família Fabaceae (Marimon et al., 2006). Essa família, devido à associação com bactérias dizatrofiticas e fungos micorrízicos, tem recebido destaque em programas de recuperação de áreas degradadas (Dias et al., 2007), justificando o seu estudo. Além disso, as espécies são bastante utilizadas pelas comunidades rurais para a exploração sustentável de seus frutos, sendo recomendadas em sistemas silvipastoris e arborização de pastagens (Carvalho, 2006).

\section{MATERIAL E MÉTODOS}

\section{Área de estudo}

Este estudo foi conduzido em uma área experimental de pastagem da Embrapa Gado de Corte, em Campo Grande-MS. O solo da área 
é do tipo Latossolo Vermelho argiloso e distrófico de textura média, com teores médios de areia, argila e silte de 567, 371 e $62 \mathrm{~g} \mathrm{~kg}^{-1}$, respectivamente, e os seguintes teores químicos $\left(\mathrm{mmol}_{\mathrm{c}} \mathrm{dm}^{-3}\right)$ : $\mathrm{Ca}(35 \%), \mathrm{Mg}(35 \%), \mathrm{Al}$ (31\%), K (24\%) e P (35\%) (Volpe et al., 2008). O clima é considerado tropical úmido (Aw), segundo a classificação de Köppen, com estação chuvosa no verão e seca no inverno. A precipitação pluvial média anual situa-se em torno de $1.500 \mathrm{~mm}$, sendo junho, julho e agosto os meses de menor precipitação. A temperatura média anual oscila de 19 a $25^{\circ} \mathrm{C}$ (Melotto et al., 2009).

\section{Desenho experimental}

Para avaliar o efeito da competição com gramineas em $D$. alata e $H$. stigonocarpa, foi realizado um experimento em blocos, em área de pasto abandonado. Foram delimitados cinco blocos ao acaso, cada um contendo duas parcelas (área $=2 \times 10 \mathrm{~m}$ ): uma com o tratamento sem gramineas e a outra com gramíneas. A distância entre as parcelas foi de cinco metros.

No tratamento em ausência de gramineas, foi realizado seu controle prévio através da aplicação do herbicida glifosato em toda a área onde a gramínea seria removida. No tratamento com gramíneas, a vegetação composta principalmente por Brachiaria decumbens foi mantida intacta. Em cada uma das parcelas, foram delimitadas 10 subparcelas $(1 \mathrm{x} 1 \mathrm{~m})$ para cada espécie. Em cada subparcela, cinco sementes de cada espécie foram dispostas em gride com distância de $10 \mathrm{~cm}$ entre elas. Assim, o número total de subparcelas por parcela foi de 20 (10 de cada espécie). Essas sementes foram coletadas de parentais localizados na Reserva Particular de Patrimônio Natural da UFMS e na Fazenda da Embrapa Gado de Corte, em Campo Grande-MS.

Após a emergência das plântulas, apenas um indivíduo foi mantido em cada subparcela, sendo os demais removidos. O número total de indivíduos de cada espécie por tratamento foi de 50. Para cada tratamento foram sorteados e marcados 25 indivíduos de cada espécie por tratamento, para realizar o estudo.

\section{Coleta dos dados}

A coleta foi iniciada em março de 2009, quando os indivíduos emitiram o primeiro par de folhas, logo após as folhas cotiledonares (dois meses após o plantio das sementes, que ocorreu em janeiro de 2009). Essa foi considerada a primeira folha da amostra de cada indivíduo.

Os dados de herbivoria, altura, crescimento e abscisão de folíolos foram coletados em março, julho, outubro e novembro de 2009 e janeiro de 2010, de acordo com a sazonalidade apresentada durante o ano; os meses de seca foram de março a outubro de 2009, e as chuvas começaram em novembro de 2009 e se estenderam até janeiro de 2010 (Figura 1).

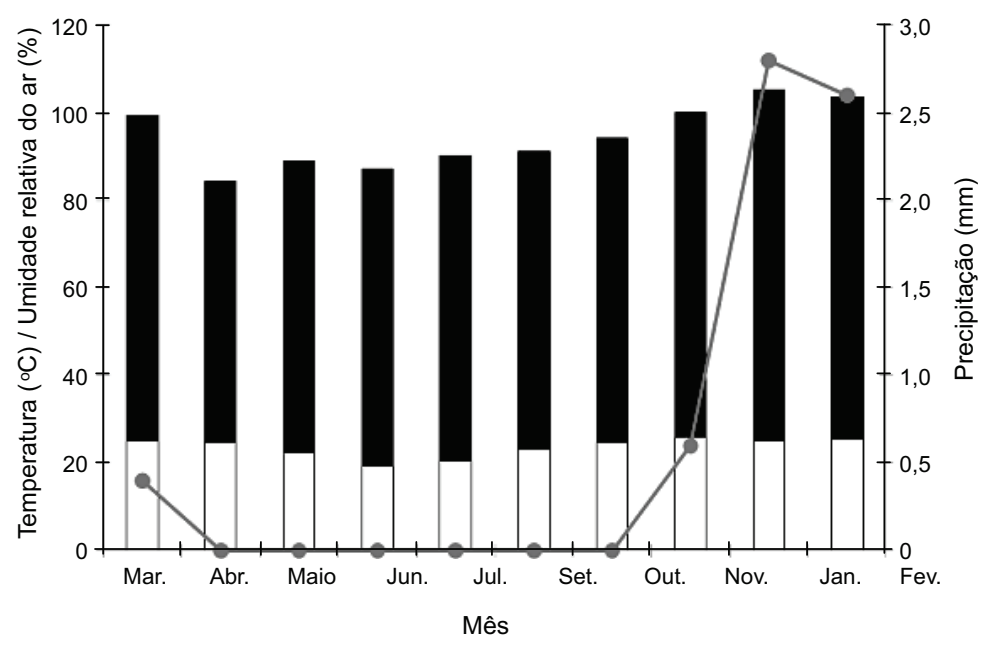

Figura 1 - Dados de precipitação pluvial média mensal (linha), umidade relativa média (barra preta) e temperatura atmosférica média (barra branca) de março de 2009 a fevereiro de 2010, da estação meteorológica localizada na Embrapa Gado de Corte, Mato Grosso do Sul, Brasil (20 $\left.45^{\prime} \mathrm{S} 54^{\circ} 61^{\prime} \mathrm{W}\right)$. 


\section{Herbivoria}

Para mensurar a herbivoria, as folhas de cada indivíduo foram fotografadas com uma máquina digital S800fd. A folha amostrada foi marcada com um arame envolvendo o pecíolo, para ser mensurada durante todo o experimento. Sem ser retirada, foi então colocada sobre um papel branco com uma régua milimetrada e fotografada.

No primeiro mês (março), uma folha de cada indivíduo foi selecionada para medir a herbivoria. Já no segundo (julho) e terceiro meses (outubro) foram selecionadas duas folhas por indivíduo ( $\mathrm{n}$ folhas por espécie por tratamento $=2 \times 25$ indivíduos). No quarto (novembro) e quinto meses (janeiro), três folhas foram escolhidas $\left(\mathrm{n}_{\text {folhas por espécie por tratamento }}\right.$ $=3 \times 25$ individuos). A seleção das folhas buscou amostrar diferentes partes da plântula (ápice, meio e base).

A imagem foi analisada no software ImageJ, onde foi determinada a área foliar $\left(\mathrm{mm}^{2}\right)$ e a área removida $\left(\mathrm{mm}^{2}\right)$ pelo herbivoro. Assim, obteve-se a taxa de herbivoria, expressa pela porcentagem da área foliar perdida, estimada segundo a fórmula:

$$
\% \text { herbivoria }=\frac{\text { área perdida }}{\text { área total }} \times 100
$$

\section{Abscisão de foliolos}

A contagem de foliolos perdidos foi feita em cada indivíduo de cada espécie, em cada tratamento ( $\mathrm{n}=25$ de cada espécie por tratamento), ao longo de todo o tempo do experimento. Os individuos selecionados foram os mesmos da avaliação da herbivoria.

\section{Desenvolvimento vegetal: diâmetro e altura}

A fim de avaliar o crescimento primário e secundário dos 25 indivíduos de cada espécie em cada tratamento, a altura foi medida com uma fita métrica graduada, e o diâmetro na altura do solo, mensurado com um paquímetro digital ao longo dos meses estabelecidos. Para analisar o crescimento das plântulas, primeiramente foi calculada a Taxa de Crescimento Relativo (TCR), conforme a fórmula:

$$
T C R=\frac{\text { LnAlt }_{2}-\text { LnAlt }_{1}}{\left(t_{2}-t_{1}\right)}
$$

em que $L n$ é o logaritmo natural; $A l t_{2}$, a altura da plântula no tempo $2 ; A l t_{1}$, a altura da plântula no tempo $1 ; t_{2}$, o tempo 2 ; e $t_{1}$, o tempo 1 . Também foi determinada a taxa de crescimento relativo, com as medidas do DAS.

\section{Teores nutricionais}

Para obter a quantidade de carbono e nitrogênio, foram coletadas amostras foliares aleatórias de 60 indivíduos (15 de cada espécie de cada tratamento), no mês de maio de 2009 . As folhas foram secas de 48 a 72 horas em estufa a $65^{\circ} \mathrm{C}$, esfriadas em dessecador, para evitar a entrada de umidade, e pesadas em balança analítica, dentro de cubetas próprias feitas de quartzo. O manuseio das cubetas foi feito com pinças, evitando deixar resíduos e gerar erros nos resultados. Após o preparo, as amostras foram colocadas no NC Analyser com cromatógrafo de hélio e oxigênio. Para definir a curva-padrão, foi utilizado acetanilide. O conteúdo de água das folhas foi calculado a partir da diferença entre o peso da folha fresca e o peso da folha seca dividido pelo peso da folha fresca.

\section{Análise de dados}

As variáveis mensuradas para avaliar a herbivoria, o crescimento e a perda de foliolos tiveram distribuição normal de acordo com o teste de Kolmogorov-Smirnov (Zar, 1998) e, portanto, foram analisadas por meio de testes paramétricos.

Para avaliar a herbivoria, a taxa de crescimento do diâmetro na altura do solo (DAS) e taxa de crescimento em altura e a perda foliar das plântulas entre indivíduos em tratamentos com e sem gramíneas ao longo do tempo, foi realizada uma Análise de Variância Fatorial de Medidas Repetidas para cada parâmetro (Zar, 1998). Os dados da porcentagem de herbivoria foram transformados em arco seno da raiz quadrada, para homogeneização das variâncias.

Para comparar o conteúdo de carbono, nitrogênio e água nas folhas das plântulas de cada espécie entre os dois tratamentos (áreas 
com e sem gramíneas), devido à não normalidade dos dados, utilizou-se o teste de MannWhitney (Zar, 1998). O nível de significância de todos os testes usados foi de $p<0,05$. Todos os testes foram realizados utilizando o programa estatístico SYSTAT 12 (2008).

\section{RESULTADOS E DISCUSSÃO}

\section{Herbivoria}

A taxa de herbivoria em $D$. alata variou significativamente entre os tratamentos $(\mathrm{F}=10,324 ; \mathrm{p}=0,003)$ e ao longo do tempo $(\mathrm{F}=15,549 ; \mathrm{p}<0,001)$ (Figura 2A). Os individuos do tratamento com gramínea apresentaram maior proporção de herbivoria que o tratamento sem gramíneas ao longo do tempo, após março de 2009. Segundo Agrawal et al. (2006), a pressão competitiva da gramínea pode reduzir a resistência vegetal e aumentar a vulnerabilidade à herbivoria.

Notou-se também que nesse mesmo tratamento a taxa de herbivoria aumentou de 10\% no primeiro mês (março) para 55\% no segundo mês amostrado (julho), decaindo a partir de então. Assim, as folhas amostradas no início do experimento não estariam sofrendo danos adicionais. Esse resultado pode estar relacionado com algumas características químicas dessas folhas, como redutores de digestibilidade ou defesas quantitativas, que geralmente têm sua concentração aumentada com a idade da folha e intensidade de herbivoria, o que pode torná-la menos vulnerável ao ataque (Kursar \& Coley, 2003).

No entanto, para as plântulas de H. stigonocarpa não houve variação da taxa de herbivoria entre os tratamentos $(\mathrm{F}=0,432$; $\mathrm{p}=0,519)$, nem ao longo do tempo $(\mathrm{F}=1,271$; $\mathrm{p}=0,289$ ) (Figura 2B). Nota-se também que a taxa de herbivoria foliar ao longo dos meses em $H$. stigonocarpa foi sempre inferior a $40 \%$. As diferentes respostas da herbivoria observadas nas duas espécies estudadas aqui quanto aos tratamentos demonstram que a influência da espécie competidora (B. decumbens) está associada às características relacionadas a desenvolvimento, nutrição e defesa vegetal da espécie nativa, bem como às suas interações com os seus herbívoros (Hanley, 2004).
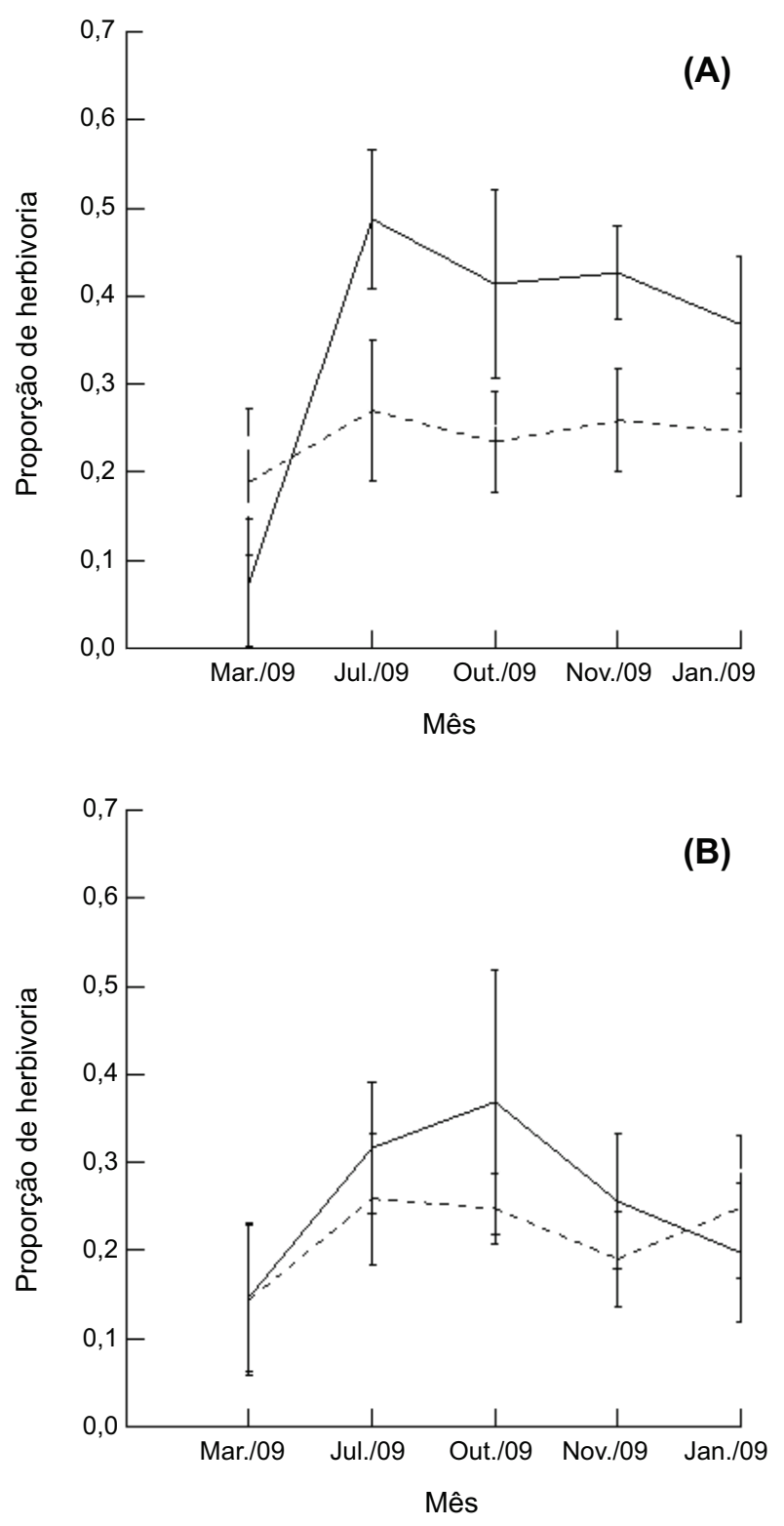

Figura 2 - Proporção de herbivoria foliar ao longo do tempo nos indivíduos de: (A) Dipteryx alata (Fabaceae) e (B) Hymenaea stigonocarpa (Fabaceae), em áreas de pastagem da Embrapa Gado de Corte, Campo Grande-MS. A linha contínua representa o tratamento com gramíneas, e a tracejada, o tratamento sem gramíneas. Em todos os gráficos estão representadas as médias \pm erro-padrão.

\section{Abscisão de foliolos}

A quantidade de foliolos perdidos em $D$. alata não variou entre os tratamentos $(\mathrm{F}=0,261 ; \mathrm{p}=0,612)$, e sim ao longo do tempo $(F=49,425 ; p<0,001 ;$ Figura 3), com crescente 


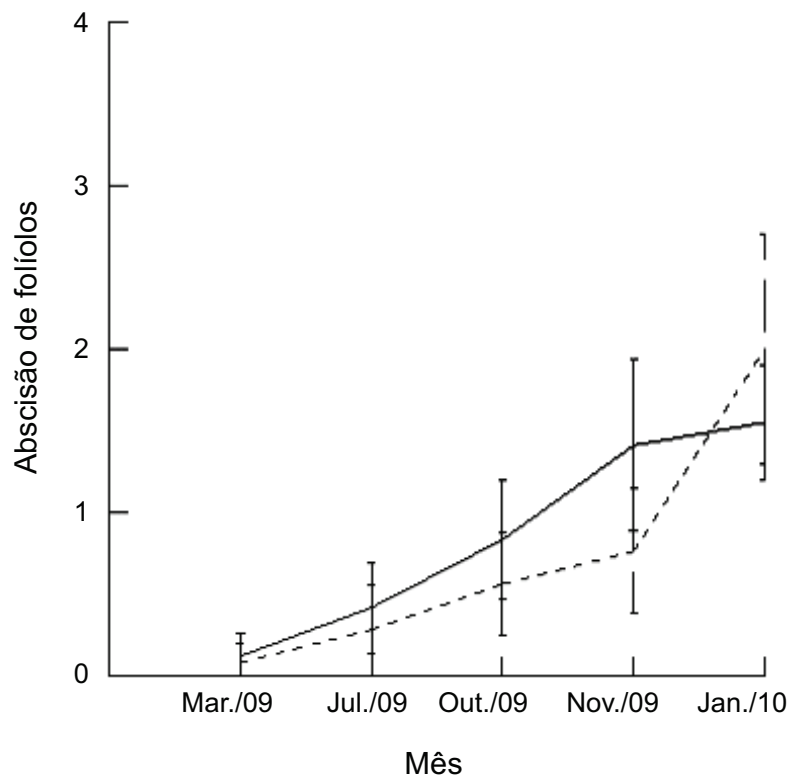

Figura 3 - Abscisão de folíolos de Dipteryx alata (Fabaceae) em áreas de pastagem da Embrapa Gado de Corte, Campo Grande-MS. A linha contínua representa o tratamento com gramíneas, e a tracejada, o tratamento sem gramíneas. No gráfico estão representadas as médias \pm erro-padrão.

perda ao longo dos meses amostrados. Pirani et al. (2009) observaram que a perda foliar dessa espécie ocorre no período de junho a setembro no Estado de Mato Grosso. A contínua e crescente perda nos meses subsequentes (novembro e janeiro) sugere que outros fatores não mensurados neste estudo, como o tempo de resposta fisiológica à intensa herbivoria, podem estar envolvidos nesse resultado.

Esse tempo de resposta por eventos fenológicos pode não ser rápido. Diferentemente, $H$. stigonocarpa não apresentou abscisão foliar, embora essa espécie possa apresentar perdas foliares de julho a outubro (Pirani et al., 2009).

\section{Desenvolvimento vegetal: diâmetro e altura}

A taxa de crescimento em altura das plântulas de $D$. alata no tratamento com gramínea foi menor que no sem gramíneas $(F=14,544$; $\mathrm{p}<0,001$ ), porém sem variação ao longo do tempo $(F=0,467 ; p=0,706$; Figura 4A). Em julho, a taxa de crescimento primário foi cerca de $90 \%$ maior no tratamento com gramínea. Segundo Mangla et al. (2011), a competição entre espécies vegetais exerce forte influência no crescimento das mesmas. Para esses autores, a competição pode ser considerada o primeiro processo limitante para o sucesso da restauração. Coincidentemente, nesse mesmo período foi observada maior herbivoria $(50-60 \%)$ em D. alata no tratamento com gramíneas. É provável que a maior pressão da herbivoria tenha influenciado no crescimento dessas plântulas, uma vez que há diminuição da área fotossintetizante, prejudicando o crescimento primário.

Em $H$. stigonocarpa não houve variação da taxa de crescimento em altura entre os tratamentos $(F=3,036 ; p=0,094)$ nem ao longo do tempo $(F=0,126 ; p=0,945$; Figura 4B). Nota-se que em $H$. stigonocarpa não houve investimento substancial em crescimento primário durante o tempo de estudo, o que impossibilita comparações entre os tratamentos.

Em relação à taxa de crescimento em diâmetro na altura do solo das plântulas de D. alata, não houve variação entre os tratamentos $(\mathrm{F}=0,165 ; \mathrm{p}=0,686)$ nem ao longo do tempo $(\mathrm{F}=0,494 ; \mathrm{p}=0,687$; Figura $4 \mathrm{C})$. Já para $H$. stigonocarpa a presença de gramíneas influenciou negativamente esse parâmetro de crescimento entre os tratamentos $(\mathrm{F}=41,193$; $\mathrm{p}<0,001)$ ao longo do tempo $(\mathrm{F}=4,202 ; \mathrm{p}=0,007)$ (Figura 4D), principalmente em outubro (91\% menor em relação ao tratamento sem gramineas). O resultado indica a maior taxa de desenvolvimento secundário observada em $H$. stigonocarpa na ausência de competição.

Os resultados das taxas de crescimento demonstram que as gramíneas prejudicam o desenvolvimento das plântulas das espécies estudadas, sendo em $D$. alata no crescimento primário e em $H$. stigonocarpa no crescimento secundário. Aparentemente, o investimento nesse estágio inicial de desenvolvimento é diferente para essas espécies, embora não haja informações disponiveis sobre o assunto. Além disso, a herbivoria também demonstrou forte relação com o crescimento vegetal das plântulas de D. alata.

\section{Teores nutricionais}

A presença das gramineas influenciou os teores nutricionais das folhas das plântulas de $D$. alata, onde se observou menor conteúdo de carbono ( $p=0,026$; Figura $5 A$ ) e maior conteúdo de nitrogênio ( $p=0,014$; Figura $5 B$ ) e água 

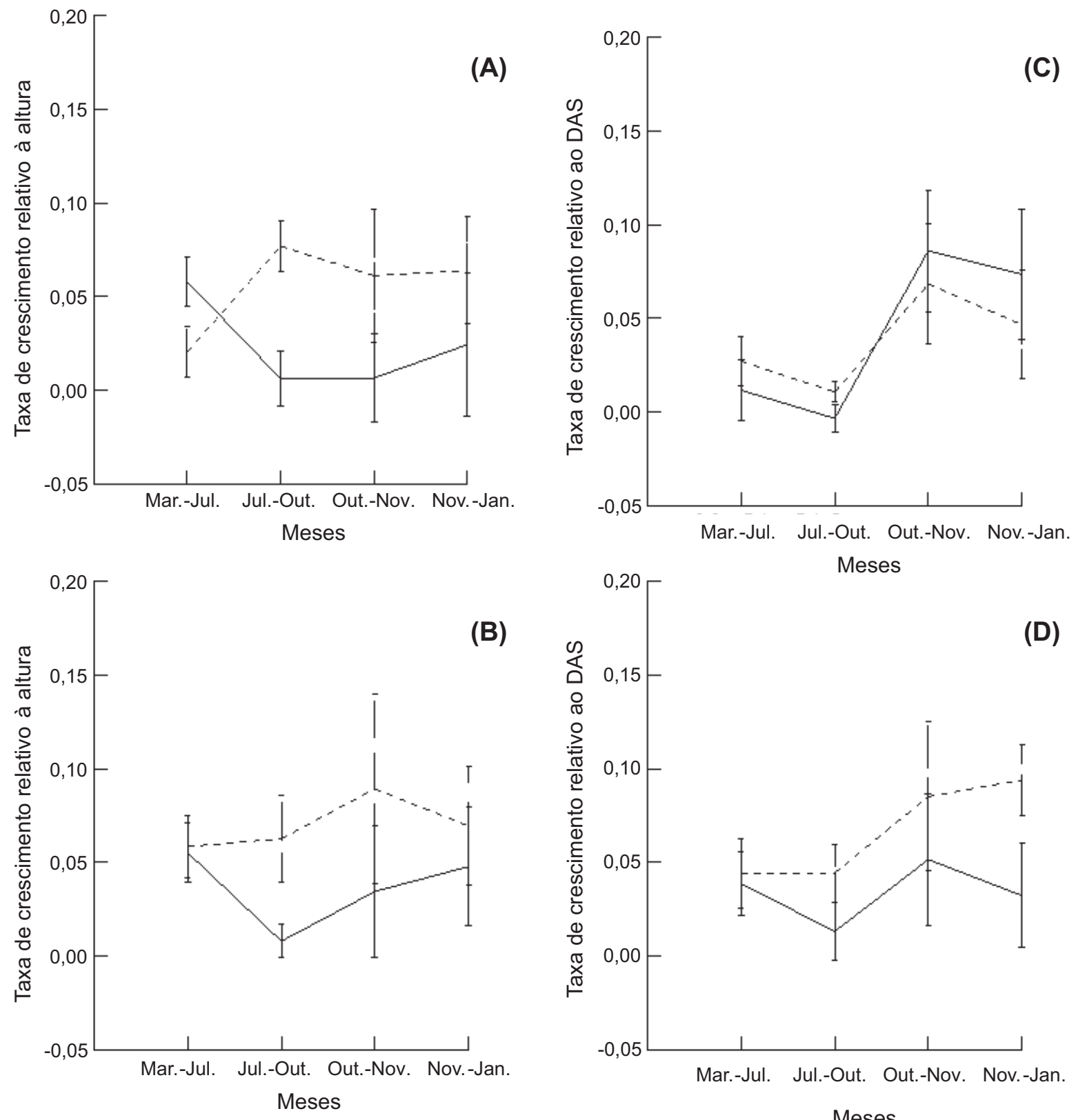

Meses

Figura 4 - Parâmetros de crescimento das plântulas em área de pastagem da Embrapa Gado de Corte, em Campo Grande-MS. Taxa de crescimento relativo (TCR) à altura de: (A) Dipteryx alata e (B) Hymenaea stigonocarpa; Taxa de crescimento relativo (TCR) ao diâmetro na altura do solo (DAS): (C) Dipteryx alata e (D) Hymenaea stigonocarpa. A linha contínua representa o tratamento com gramíneas, e a linha tracejada, o tratamento sem gramíneas. Em todos os gráficos estão representadas as médias \pm erro-padrão.

$(\mathrm{p}<0,001$; Figura 5C). A maior concentração de nitrogênio pode estar associada à diminuição da taxa de nitrificação através de um inibidor presente nas raízes das gramíneas, como observado em Brachiaria humidicola, ocasionando menor perda de nitrogênio e emissão de óxido nitroso $\left(\mathrm{N}_{2} \mathrm{O}\right)$ para a atmosfera (Subbarao et al., 2009). Aparentemente, a maior disponibilidade nutricional para as folhas de $D$. alata no tratamento com gramíneas exerceu forte influência na proporção de herbivoria, comparado ao tratamento sem gramíneas, cujas folhas tinham menor conteúdo de nitrogênio e água. 

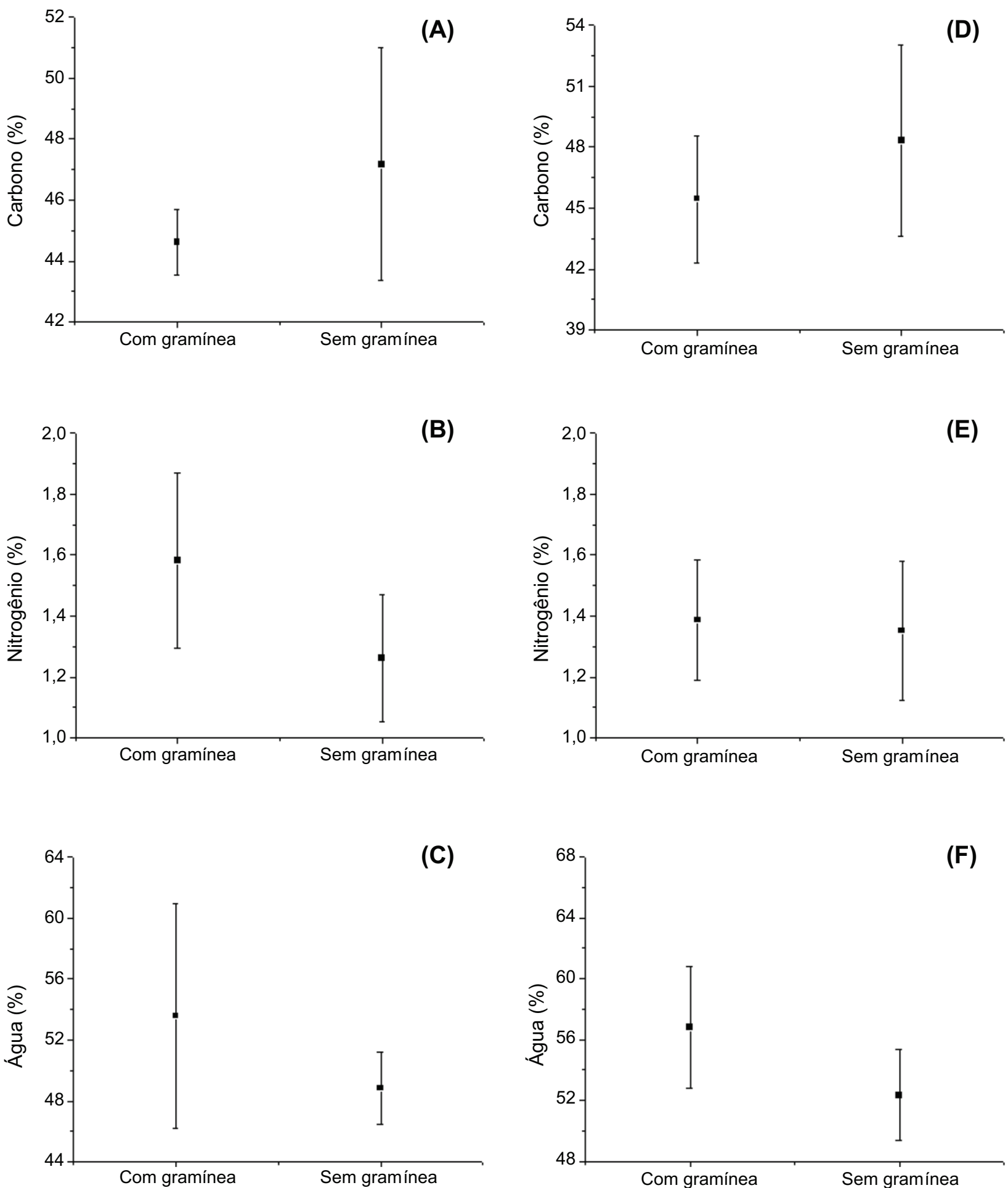

Figura 5 - Porcentagem nutricional foliar em áreas com e sem gramíneas da Embrapa Gado de Corte, em Campo Grande-MS, das plântulas de Dipteryx alata: (A) carbono, (B) nitrogênio e (C) água; e de Hymenaea stigonocarpa: (D) carbono, (E) nitrogênio e $(\mathrm{F})$ água. Em todos os gráficos estão representadas as médias \pm erro-padrão. 
O nitrogênio é um dos principais nutrientes das plantas que são vitalmente importantes na sobrevivência e no desenvolvimento dos herbivoros. Muitas vezes, quando a disponibilidade de nitrogênio é alta nas plantas, os compostos formados à base de carbono diminuem em concentração (Millard \& Way, 2011); assim, o menor conteúdo de carbono pode indicar maior disponibilidade nutricional para herbívoros. Esse balanço entre carbono e nitrogênio parece ser evidente nas plântulas de D. alata, onde o tratamento com gramínea obteve maior quantidade de nitrogênio e menor de carbono, favorecendo a herbivoria.

Em $H$. stigonocarpa, o teor de carbono foi menor em tratamentos com gramíneas $(p=$ 0,017; Figura 5D). O menor ganho de carbono observado nesse tratamento pode ser resultado do sombreamento das gramíneas (SalgadoLuarte \& Gianoli, 2010). Por outro lado, nessa espécie não foi encontrada diferença significativa nos teores de nitrogênio entre os tratamentos ( $p=0,306$; Figura $5 E$ ), enquanto o conteúdo de água foi maior no tratamento com graminea ( $p=0,006$; Figura $5 F)$.

A ausência de diferença na concentração de nitrogênio em $H$. stigonocarpa possivelmente refletiu na ausência de diferenças nas taxas de herbivoria entre os tratamentos. Sabe-se que os diferentes grupos de animais herbivoros apresentam demanda nutricional de recurso distinta (Futuyma \& Agrawal, 2009). Assim, conforme a comunidade de herbivoros associada à planta hospedeira, a disponibilidade de um determinado nutriente pode não alterar as taxas de herbivoria neles.

\section{CONSIDERAÇÕES FINAIS}

Com base nos dados encontrados, pode-se dizer que cada espécie vegetal responde fisiologicamente de forma distinta (crescimento e assimilação de nutrientes), bem como varia a suscetibilidade aos danos pelos herbívoros associados, em ambientes sob competição por recursos com B. decumbens. Conclui-se que, para o estabelecimento de plântulas de D. alata em áreas de pastagens, a ausência de $B$. decumbens propiciará maior sucesso. Em contrapartida, a presença de gramínea não afeta diretamente o estabelecimento das plântulas de $H$. stigonocarpa. As informações deste estudo acrescentam subsídios que buscam auxiliar no manejo e na recuperação de áreas degradadas do Cerrado, onde a escolha de uma espécie vegetal tolerante às condições ambientais impostas pelo plantio de gramíneas exóticas é crucial para o sucesso da restauração vegetal.

\section{AGRADECIMENTOS}

A R. G. Fernandes, W. S. Covre, A. P. Paniagua, N. Paludetto, G. J. Barônio, Dr. V. A. Laura, I. M. Naka e Dr. G. Graciolli, pela ajuda durante a execução do trabalho. Ao CNPq (15.1817/2008-1, 55.9279/2008-6), à Fundação de Amparo à Pesquisa do Estado de Minas Gerais - FAPEMIG (Proc. RDP-00048-10, APQ-02158-10, APQ-04105-10, APQ 01278-08, CRA 495/07), à Capes (Proc. 2-2009) e FUNDECT (Proc. 23/200.205/2009).

\section{LITERATURA CITADA}

AGRAWAL, A. A. et al. Community heterogeneity and the evolution of interactions between plants and insects herbivores. Quart. Rev. Biol., v. 81, n. 4, p. 349-376, 2006.

CARVALHO, P. E. R. Espécies arbóreas brasileiras. Brasília: Embrapa Informação Tecnológica/Colombo: Embrapa Florestas, 2006. 627 p. (Coleção Espécies Arbóreas

Brasileiras, v. 2)

CELIS, G.; JOSE, S. Restoring abandoned pasture land with native tree species in Costa Rica: effects of exotic grass competition and light. For. Ecol. Manag., v. 261, n. 10, p. 1598-1604, 2011.

DIAS, P. F. et al. Análise do comportamento de espécies leguminosas arbóreas introduzidas em pastagens de gramíneas tropicais. Pesq. Agropec. Trop., v. 37, n. 1, p. 31-37, 2007.

EICHHORN, M. P.et al. Herbivory of tropical rainforest tree seedlings correlates with future mortality. Ecology, v. 91, n. 4, p. 1092-1101, 2010.

FORKNER, R. E. Timing is everything? Phenological synchrony and population variability in leaf chewing herbivores of Quercus. Ecol. Entomol., v. 33, n. 2, p. 276285, 2008.

FUTUYMA, D. J.; AGRAWAL, A. A. Macroevolution and the biological diversity of plants and herbivores. PNAS, v. 106, n. 43, p. 18054-18061, 2009.

HANLEY, M. E. Seedling herbivory and the influence of plant species richness in seedling neighborhoods. Plant Ecol., v. 170, n. 1, p. 35-41, 2004.

Planta Daninha, Viçosa-MG, v. 30, n. 4, p. 737-746, 2012 
KLINK, C. A.; MACHADO, R. B. A conservação do Cerrado brasileiro. Megadiversidade, v. 1, n. 1, p. 147-155, 2005.

KURSAR, T. A.; COLEY, P. D. Convergence in defense syndromes of young leaves in tropical rainforest. Biochem. System. Ecol., v. 31, n. 8, p. 929-949, 2003.

LEVINE, J. M. et al. Mechanisms underlying the impacts of exotic plants invasions. Proc. Royal Soc. London, v. 270, n. 1517 , p. $775-781,2003$

MANGLA, S. et al. Intra and interspecific competition among invasive and native species during early stages of plant growth. Plant Ecol., v. 212, n. 4, p. 531-542, 2011.

MARIMON, B. S. et al. Observations on the vegetation of northeastern Mato Grosso, Brazil. IV. An analysis of the Cerrado-amazonian fortest ecotone. Edinburgh J. Bot., v. 63, n. $2-3$, p. $323-341,2006$

MATOS, D. M. S.; PIVELLO, V. R. O impacto das plantas invasoras nos recursos naturais de ambientes terrestres alguns casos brasileiros. Ci. Cult., v. 61, n. 1, p. 27-30, 2009.

MELOTTO, A. et al. Sobrevivência e crescimento inicial em campo de espécies florestais nativas do Brasil central indicadas para sistemas silvipastoris. R. Árvore, v. 33, n. 3, p. 425-432, 2009.

MILLARD, P.; WAY, D. A. Tree competition and defense against herbivores: currency matters when counting the cost. Tree Physiol., v. 31, n. 6, p. 579-581, 2011.
PIRANI, F. R.; SANCHEZ, M.; PEDRONI, F. Fenologia de uma comunidade arbórea em Cerrado sentido restrito, Barra do Garças, MT, Brasil. Acta Bot. Bras., v. 23, n. 4, p. 1096-1109, 2009.

RIZZARDI, M. A. et al. Competição por recursos do solo entre ervas daninhas e culturas. Ci. Rural, v. 31, n. 4, p. $707-714,2001$

SADY, G. C. et al. Germination and survival of tree seeds in tropical montane forest restoration study (Costa Rica). Ecol. Restor., v. 28, n. 1, p. 121-124, 2010.

SALGADO-LUARTE, C.; GIANOLI, E. Herbivory on temperate rainforest seedlings in sun and shade: resistance, tolerance and habitat distribution. PlosOne, v. 5, n. 7, p. 1-7, 2010 .

SILVA, D. M.; BATALHA, M. A. Defense syndromes against herbivory in a Cerrado plant community. Plant Ecol., v. 212, n. 2, p. 181-193, 2011.

SUBBARAO, G. V. et al. Evidence for biological nitrification inhibition in Brachiaria pastures. PNAS, v. 106, n. 41, p. 17302-17307, 2009.

VOLPE, E. et al. Acúmulo de forragem e características do solo e da planta no estabelecimento de capim-massai com diferentes níveis de saturação por bases, fósforo e nitrogênio. R. Bras. Zootec., v. 37, n. 2, p. 228-237, 2008.

ZAR, J. H. Biostatistical analysis. 4.ed. Nova Jersey: Prentice-Hall, 1998. 930 p. 